\title{
Genetic Variants of Lipoprotein Lipase and Regulatory Factors Associated with Alzheimer's Disease Risk
}

\author{
Kimberley D. Bruce ${ }^{1, *}$, Maoping Tang ${ }^{1}$, Philip Reigan ${ }^{2}$ and Robert H. Eckel ${ }^{1}$ (I) \\ 1 Division of Endocrinology, Metabolism, and Diabetes, Department of Medicine, University of Colorado \\ Anschutz Medical Campus, Aurora, CO 80045, USA; maoping.tang@cuanschutz.edu (M.T.); \\ robert.eckel@cuanschutz.edu (R.H.E.) \\ 2 Department of Pharmaceutical Sciences, Skaggs School of Pharmacy and Pharmaceutical Sciences, \\ University of Colorado Anschutz Medical Campus, Aurora, CO 80045, USA; philip.reigan@cuanschutz.edu \\ * Correspondence: kimberley.bruce@cuanschutz.edu
}

Received: 14 October 2020; Accepted: 4 November 2020; Published: 6 November 2020

\begin{abstract}
Lipoprotein lipase (LPL) is a key enzyme in lipid and lipoprotein metabolism. The canonical role of LPL involves the hydrolysis of triglyceride-rich lipoproteins for the provision of FFAs to metabolic tissues. However, LPL may also contribute to lipoprotein uptake by acting as a molecular bridge between lipoproteins and cell surface receptors. Recent studies have shown that LPL is abundantly expressed in the brain and predominantly expressed in the macrophages and microglia of the human and murine brain. Moreover, recent findings suggest that LPL plays a direct role in microglial function, metabolism, and phagocytosis of extracellular factors such as amyloid- beta (A $\beta$ ). Although the precise function of LPL in the brain remains to be determined, several studies have implicated LPL variants in Alzheimer's disease (AD) risk. For example, while mutations shown to have a deleterious effect on LPL function and expression (e.g., N291S, HindIII, and PvuII) have been associated with increased AD risk, a mutation associated with increased bridging function (S447X) may be protective against AD. Recent studies have also shown that genetic variants in endogenous LPL activators (ApoC-II) and inhibitors (ApoC-III) can increase and decrease AD risk, respectively, consistent with the notion that LPL may play a protective role in AD pathogenesis. Here, we review recent advances in our understanding of LPL structure and function, which largely point to a protective role of functional LPL in AD neuropathogenesis.
\end{abstract}

Keywords: lipoprotein lipase; Alzheimer's disease; microglia; lipoproteins; apoproteins

\section{Introduction}

Alzheimer's disease (AD) is a devastating and ultimately fatal age-associated neurodegenerative disease. Currently, 5.8 million Americans are living with AD. Of these individuals, $81 \%$ are 75 or older [1]. In fact, it has been estimated that $32 \%$ of individuals that reach the age of 85 will have AD [1]. $\mathrm{AD}$ is characterized by increased deposition (or impaired clearance) of amyloid-beta (A $\beta$ ) deposits, the formation of neurofibrillary tangles, tau protein, and neuroinflammation [2]. However, all drugs currently approved by the US Food and Drug Administration (FDA) for the treatment of AD modulate neurotransmitters, and do not target the evolution of the disease. The current standard of care for AD includes cholinesterase inhibitors (ChEIs, e.g., donepezil) and partial $\mathrm{N}$-methyl-D-aspartate (NMDA) antagonists (e.g., memantine), or a combination therapy (e.g., Namzaric). While these treatments may address some of the primary and secondary symptoms of $\mathrm{AD}$, they are unable to prevent or delay $\mathrm{AD}$ onset or progression. Therefore, there is an urgent medical need for the design of disease-modifying therapeutics (DMTs) that specifically target the underlying mechanisms of AD neuropathogenesis to 
improve the quality of life and clinical outcomes for patients with, and at risk for, AD. To develop such therapeutics, novel targets with the potential to modify AD risk require identification.

Lipoprotein lipase (LPL) is a secretory protein primarily involved in the hydrolysis of triglycerides (TG) in TG-rich chylomicrons and very-low-density lipoproteins (VLDL). Therefore, LPL has traditionally been a mechanistic target for the development of TG lowering medications to ameliorate cardiovascular disease (CVD). However, previous work from our laboratory has shown that LPL is expressed in several regions of the central nervous system (CNS), including the brain, spinal cord, and peripheral nerves [3-5]. In addition, recent RNA-seq studies have shown that LPL is predominantly expressed by macrophages and microglia in the human brain, and expressed by macrophages, microglia, and oligodendrocyte precursor cells (OPCs) in the murine brain [6,7]. Importantly, LPL has been repeatedly implicated in AD pathogenesis. Specifically, loss-of-function LPL polymorphisms have been linked to increased AD risk [8]. Whereas patients with a gain-of-function LPL polymorphism (S447X) have increased LPL activity, lower VLDL-TG, and reduced amyloid plaque formation [9]. There is a growing body of literature highlighting the importance of LPL in microglial function [10-13]. Indeed, research from our laboratory has recently shown that LPL is a feature of anti-inflammatory microglia, which are involved in A $\beta$ phagocytosis and lipid uptake [12,13]. Although studies aimed at elucidating the function of LPL in the CNS are ongoing, since lipid and lipoprotein metabolism in the CNS plays a major role in AD risk, it is plausible that LPL contributes to AD pathology via these processes. In this review, we detail recent advances in our understanding of LPL function and biology, and critically evaluate evidence supporting a genetic association between LPL and AD. In this article, we are the first to map LPL variants to a recent crystal structure of LPL [14], and review recent studies investigating the functional significance of these variants. Moreover, we discuss emerging evidence suggesting that factors that regulate LPL function and processing may also contribute to AD risk, further highlighting the role of LPL in the neuropathogenesis of AD.

\section{LPL: Structure, Function, and Regulation}

The human LPL gene (synonyms include LIPD and HDLCQ11) is found on chromosome 8p21.3, and contains 10 exons and 11 introns, and encodes a 475 amino acid protein (Figure 1). It is important to note that the base numbering has been updated since initial characterization and modeling of the LPL enzyme, resulting in a discrepancy between the numbering of the amino acids modified in a given variant. For example, the LPL variant Asn291Ser, (rs268) is actually found at position 318, and is therefore also known as Asn318 (Figure 1). Similarly, variant S447X is actually at position 474 (Figure 1). These inconsistencies have arisen because of a change in the number of the bases in the LPL gene during human reference genome Build 37, and, due to updated models for LPL structure (see below). There is also a discrepancy in the literature regarding the number of exons contained within the protein, which may reflect splice variants, however, the functional significance of these has not yet been determined. Interestingly, many mutations in the LPL gene are found in exons 4,5, and 6, including missense, nonsense, frameshift, insertion, and duplication mutations [15].

The LPL enzyme can be catalytically active as a homodimer composed of two glycosylated $55 \mathrm{kDa}$ subunits connected by non-covalent interactions in a 'head-to-tail'-orientation [16,17]. Structural homology modeling has indicated that LPL has a similar structure to pancreatic lipase (PL) [18]. However, recent crystallography studies have improved our understanding of LPL structure and function. The crystal structure of LPL (in complex with glycosylphosphatidylinositol-anchored high-density lipoprotein binding protein 1 [GPIHBP1]) was recently resolved, and has shown that LPL can be active as a monomeric 1:1 (LPL:GPIHBP1) complex [19]. In addition, the crystal structure of LPL:GPIHBP1 with an inhibitor bound to the active site of LPL, has provided the first crystal structure where the lid and lipid-binding regions necessary for TG-rich lipoprotein (TRL) recognition are visible [14]. Here, we have annotated the structure from Arora et al., with mutations that alter LPL function (Figure 1). 


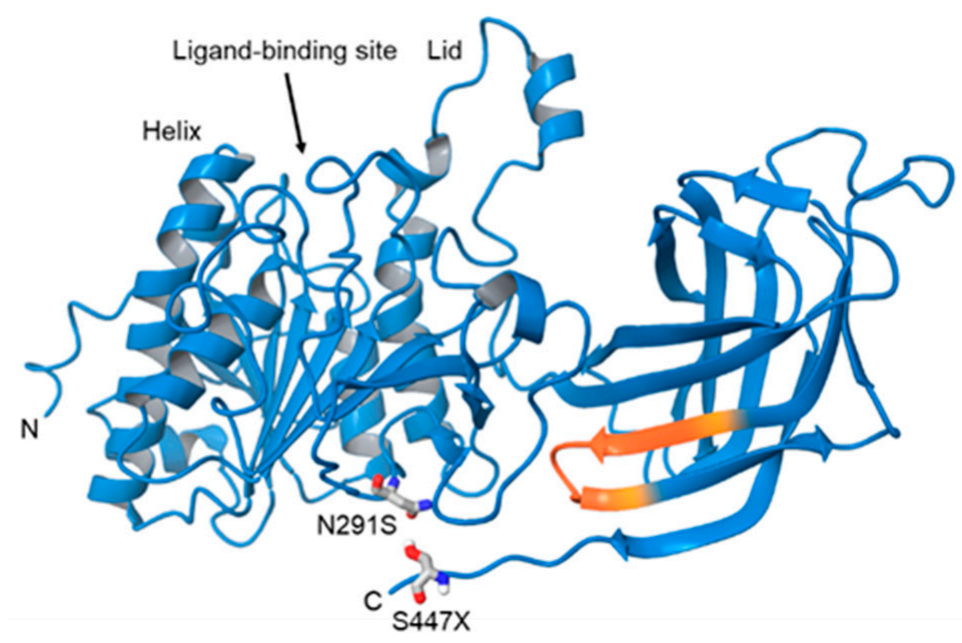

Figure 1. Tertiary structure of LPL. Ribbon representation of human LPL with residues of key mutation sites N291S and S447X shown in stick display style (carbons colored grey), exposed residues 405-414 upon S447X mutation are colored orange on the ribbon. The structure has been modified from the PDB: $6 \mathrm{OB} 0$ crystal structure elucidated by Arora et al., as residues K472, K473, S474, and G475 were added to the C-terminus, using the build feature of the Schrodinger Suite 2018-4. The ligand-binding (active) site situated between the lid and lid-proximal Helix. The N291S (residue 318) mutation, and S447X (residue 474) mutations are labeled. Hayne et al., proposed that truncation of the $C$-terminus via the S447X mutation, results in the exposure of a lipoprotein receptor binding site at residues 405-414 (highlighted in orange), suggesting increased lipoprotein receptor binding in this variant.

Although the regulation of LPL activity is not fully understood in the CNS, in the periphery, catabolism of TRL particles is known to be dependent on a number of factors that regulate LPL processing (Figure 2). For example, Lipase Maturation Factor 1 (LMF1) is a chaperone protein of the endoplasmic reticulum that is required for folding and secretion of LPL [20]. In addition, LMF1 facilitates the formation of the correct intermolecular disulfide bonds in the LPL protein [21]. Following secretion (from heart, muscle, and adipose tissue cells), LPL is tethered to heparan sulfate proteoglycans (HSPGs) in the endothelium [14], where it acts to liberate (FFAs) for uptake by key metabolic tissues. However, LPL can easily dissociate from these sites and re-associate with cell surface receptors and act as a molecular bridge to facilitate uptake and catabolism of lipoproteins [22]. These include receptors involved in lipoprotein endocytosis, such as the LDL receptor-related protein/ $\alpha 2$-macroglobulin receptor (LRP), GP330/LRP-2 (Megalin), and VLDL receptors [23]. In addition, LPL binds to Sortilin with a similar affinity as LRP. Moreover, this interaction can be inhibited by the receptor-associated protein (RAP) and neurotensin, suggesting that LPL and RAP compete for interaction with Sortilin [24]. Since RAP-deficient adipocytes secrete poorly assembled LPL, it has been suggested that RAP may prevent premature interaction of LPL with binding partners in the secretory pathways such as LRP and HSPGs [25] (Figure 2).

In addition to factors associated with trafficking and processing, there are several endogenous proteins associated with LPL inhibition. The angiopoietin-like proteins (ANGPTL) 3,4, and 8 inactivate LPL activity by catalyzing the unfolding of LPL's hydrolase domain [26,27] (Figure 2). ANGPTL4 is one of the best characterized LPL inhibitors and has recently been shown to unfold the catalytic domain of LPL in sub-stoichiometric amounts [28]. Importantly, the binding of GPIHBP1 to LPL protects LPL from ANGPTL4-mediated unfolding [28]. ANGPTL3 inhibits LPL activity in vitro and can also inhibit endothelial lipase, which catalyzes the hydrolysis of phospholipids in circulating lipoproteins, mostly high-density lipoproteins (HDL) [29,30]. Importantly ANGPTL3-mediated inhibition of LPL in vivo requires activation by ANGPTL8, which is similarly located in the intron of a DOCK (dedicator of cytokinesis) gene [31], suggesting divergent functions emerging through evolution. 


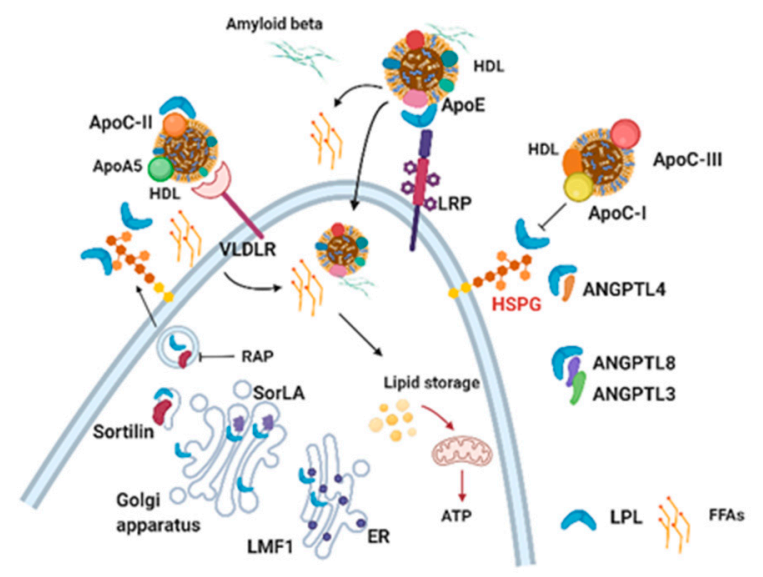

Figure 2. Schematic representation of LPL processing and function. LPL is chaperoned through the ER by LMF1, and sorted through the Golgi apparatus by SorLA/Sortilin. RAP can inhibit Sortilin binding, which may prevent premature secretion and affiliation with lipoprotein receptors (e.g., VLDLR and LRP). Secreted LPL is tethered to the cell surface to HSPG, where is may form a complex with lipoprotein receptors. In the brain, it is unknown whether LPL can hydrolyze the lipid components of lipoproteins, and if the canonical activators (i.e., ApoC-II and ApoA5) are involved. LPL may facilitate the endocytosis of lipoproteins via an interaction with cell surface lipoprotein receptors, providing lipids to the cell for storage, membrane formation or energy utilization. LPL also facilitates the endocytosis of A $\beta$, which may be HDL bound. ApoC-I and ApoC-III inhibit LPL activity. ANGPLT4 binds to the active site of LPL to inhibit hydrolytic activity. This schematic is largely based on our understanding of LPL function in microglia, and LPL processing may vary in other cells types.

The apolipoproteins (Apo) C-I and C-III are also known to inhibit LPL activity (Figure 2). However, unlike the ANGPTLs, ApoC-I, and ApoC-III are thought to prevent LPL from binding to lipid particles, thus negatively regulating LPL-activity and rendering the enzyme more susceptible to irreversible inactivation by ANGPTL4 [32] (Figure 2). APOE is another apoprotein associated with negative regulation of LPL. Specifically, APOE inhibits LPL-mediated lipolysis of chylomicron-like emulsions in vivo and in vitro [33]. Importantly, APOE is expressed at extremely high levels in the brain, and some isoforms of APOE (APOE4) are associated with the neuropathogenesis of AD. However, a role for APOE in the regulation of LPL in the CNS has not been investigated.

In addition to endogenous inhibitors, there are also endogenous activators of LPL activity. ApoA5 increases LPL activity and has been proposed to direct VLDL and chylomicrons to proteoglycan bound-LPL [34]. ApoC-II is a promiscuous apoprotein constituent of all lipoproteins, including very low-density lipoproteins (VLDL) that are needed for LPL activation [35]. Interestingly, a synthetic fragment of ApoC-II (residues 55-78) is capable of activating LPL activity 12-fold, compared to 13-fold for the intact protein [36]. Also, of note is the fact that ApoC-II is predominantly expressed in the macrophage and microglia of both the human and mouse brain [6]. However, in the human brain, ApoC-II is also expressed by oligodendrocytes and mature astrocytes [6,7]. A putative role for ApoC-II in the brain has not been investigated.

Other proteins within the apoproteins family play a role in lipid and cholesterol homeostasis in the brain, and therefore it is plausible to speculate that they may directly or indirectly interact with LPL. For example, clusterin (CLU), which is also known at ApoJ, is considered the third greatest risk factor for late-onset AD (LOAD), following ApoE and BIN1 [37,38]. CLU's role in A $\beta$ uptake and clearance most likely underlies its association with $\mathrm{AD}$ neuropathogenesis. Although there have been reports that CLU facilitates [39] and impedes A $\beta$ clearance [40], it is argued that the outcome of the interaction relates to the CLU: $\mathrm{A} \beta$ ratio, and that either factor in excess determines a neuroprotective or neurotoxic outcome [41,42]. Recently, it has been suggested that CLU and ApoE are both involved in the lipidation and triggering receptor expressed on myeloid cells (TREM2)-mediated clearance of $\mathrm{A} \beta$ by microglia [43]. Since LPL and TREM2 are co-expressed in microglia [11], and both factors are 
involved in lipoprotein processing, it is likely that CLU and TREM2 functionally contribute to AD pathology. However, a direct interaction has yet to be reported and further studies are warranted.

\section{LPL in the Central Nervous System}

LPL is expressed in the brain, spinal cord, and peripheral nerves [3-5], and is predominantly expressed by macrophages and microglia in the human and murine brain [6]. We have previously shown that neuronal-LPL is associated with the central regulation of systemic metabolism $[44,45]$. Mice lacking neuronal LPL become obese and have a specific depletion in polyunsaturated fatty acids (PUFAs) $[45,46]$. In addition, hypothalamic neurons lacking LPL show altered substrate metabolism in vitro and in vivo, and systemic substrate metabolism in vivo [47]. In primary neurons, LPL activity has been shown to be negatively regulated by the sortilin-related receptor (SorLA/sortilin) [48]. Specifically, SORL1, which encodes SorLA (further processed to sortilin), expression is associated with increased accumulation of LPL within endosomal compartments, which is ultimately routed to the lysosomes for degradation and prevents LPL from being secreted [48].

Several studies have also demonstrated putative roles for LPL in glia. For example, LPL expression is increased in primary cultures of hypothalamus-derived astrocytes, whereas palmitic acid and TGs reduce LPL expression ex vivo [49]. Moreover, astrocyte-specific depletion of LPL in vivo, exacerbates high-fat diet-induced obesity, suggesting that astrocyte-derived LPL is involved in central homeostasis and peripheral metabolism [49]. LPL can bind to $A \beta$, which promotes glycosaminoglycan-dependent uptake of A $\beta$ by astrocytes [50]. Interestingly, ANGPTL4 is abundantly expressed in white matter astrocytes, and its expression is markedly reduced in active multiple sclerosis (MS) lesions [51].

Recent data suggests that LPL regulates microglial metabolism and phagocytosis, which may underlie a role in the development of AD. Several single-cell RNAseq (scRNAseq) analyses of microglia ex vivo, have defined the transcriptomic identities of microglial phenotypes throughout aging, across brain regions [52-54], and during disease [11,53,55]. A microglial phenotype with tightly regulated lipid and lipoprotein metabolism has been consistently observed. For example, Keren-Shaul et al., 2017 observed disease-associated microglia (DAMs) in aged 5XFAD mice characterized by markedly increased expression of genes associated with lipid and lipoprotein metabolism (e.g., APOE, LPL, TREM2), suggesting that lipid uptake, utilization, or metabolism is increased in these microglial sub-populations [11]. Interestingly, elevated LPL expression is also a feature of microglial clusters observed during early postnatal life (P4/P5) [53], in proliferative-region-associated-microglia (PAMs) [54], in the demyelinating brain [53], and in the latter stages of neurodegeneration [55]. While its precise function remains elusive, we have previously shown LPL is a feature of phagocytic and 'reparative' microglia and is involved in microglial lipid and lipoprotein uptake [1]. LPL depletion in BV-2 microglia (LPL KD) also causes a profound inflammatory polarization [1]. Taken together, these data suggest that LPL is involved in lipid and lipoprotein uptake, which may provide the lipid substrates needed for homeostatic microglial functions such as oxidative metabolism and phagocytosis.

\section{LPL Variants and AD}

Polymorphisms in the LPL gene that encode non-functioning LPL proteins lead to LPL deficiency, also known as familial chylomicronemia syndrome (FCS) [56]. FCS is a rare (1 in 1 million) autosomal recessive disorder and involves impaired clearance of chylomicrons and VLDL from plasma leading to serious clinical consequences such as acute and recurring pancreatitis which can be fatal [56]. Although clinical investigations regarding the association between familial LPL deficiency and $\mathrm{AD}$ are lacking, neuropsychiatric findings have been reported, such as depression, memory loss, schizophrenia [57], and dementia.

The N291S (rs268) polymorphism occurs in exon 6 of the LPL gene and results in an A-G substitution (Table 1). In silico analysis suggests that this substitution leads to changes in the secondary structure of LPL, and changes in the hydrophobicity and flexibility of residues 314-322 near the ligand-binding 
site, which is detrimental to LPL function [58]. Several studies have reported that individuals with the N291S allele have higher circulating TGs but lower HDL-cholesterol (HDL-C) [59-62]. While the prevalence of N291S is around 1\% of the general population, N291S is over-represented (5\%) in patients diagnosed with $A D$, suggesting that the loss of function LPL variant plays a role in AD pathogenesis [63]. Computational analysis suggests that the amino acid substitution that occurs at position 318 in the N291S variant results in changes the hydrophobicity and flexibility of residues 314-322 near the ligand binding site [58]. Although studies investigating prevalence in relatively small cohorts have reported no association with N291S and AD risk, larger analysis and meta-analysis have reported that $\mathrm{N} 291 \mathrm{~S}$ is a predisposing factor of $\mathrm{AD}[8]$.

Table 1. Functional and Clinical Characteristics of LPL Variants Associated with AD Risk

\begin{tabular}{|c|c|c|c|c|}
\hline Mutation & $\begin{array}{c}\text { Effect on LPL Structure or } \\
\text { Function }\end{array}$ & AD Form & $\begin{array}{c}\text { Prevalence } \\
\text { (\% of Population) }\end{array}$ & Clinical Characteristics \\
\hline $\begin{array}{l}\text { N291S, } \\
\text { Asn291Ser } \\
\text { (rs268). Also } \\
\text { known as } \\
\text { Asn318 }\end{array}$ & $\begin{array}{l}\text { Mutation in exon } 6 \text { results } \\
\text { in an A-G transmission } \\
\text { [59]. Amino acid } \\
\text { substitution occurs at base } \\
318 \text { changes the } \\
\text { hydrophobicity and } \\
\text { flexibility of residues } \\
\text { 314-322 near the ligand } \\
\text { bindings site [58]. }\end{array}$ & & $2-5 \%[64]$ & $\begin{array}{c}\text { Higher TG, lower HDL } \\
\text { (11427211). } \\
\text { Overrepresented in } \\
\text { patients diagnosed with } \\
\text { AD (5\% versus } 1 \%[63])\end{array}$ \\
\hline HindIII (rs320) & $\begin{array}{l}\text { T-G substitution in intron } \\
\text { 8, at position } 481 \text { removing } \\
\text { HindIII restriction site }\end{array}$ & LOAD [65] & $\begin{array}{c}\text { 25-39\% PMID: } \\
10830909\end{array}$ & $\begin{array}{l}\text { Increased plasma lipid } \\
\text { profile and susceptibility } \\
\text { to CAD. Significant } \\
\text { association (1.75-fold } \\
\text { increased risk) with LOAD } \\
\text { in an Iranian population } \\
\text { [65]. Homozygous } \\
\text { genotypes have an } \\
\text { increased risk of AD, more } \\
\text { so in females [66]. }\end{array}$ \\
\hline $\begin{array}{l}\text { PvuII (rs285) } \\
\text { Also referred to } \\
\text { as the P+ allele. }\end{array}$ & $\begin{array}{l}\text { Mutation in intron } 6 \\
\text { within PvuIII restriction } \\
\text { site. Potential cis-element } \\
\text { of unknown significance. } \\
\text { PvuIII is associated with } \\
\text { altered LPL mRNA [67]. }\end{array}$ & SAD [67] & $\begin{array}{l}\text { 39\% PMID: } \\
10830909\end{array}$ & $\begin{array}{l}\text { Increased risk of AD in P+ } \\
\text { carriers. Reduced cortex } \\
\text { cholesterol, increased } \\
\text { NFTs and senile plaques. } \\
\text { Combined effect of P+ and } \\
\text { ApoE4 in the fusiform } \\
\text { gyrus in eastern Canadian } \\
\text { population [67]. }\end{array}$ \\
\hline $\begin{array}{l}\text { S447X (rs328). } \\
\text { Also known as } \\
\text { Ser447Ter. }\end{array}$ & $\begin{array}{l}\text { Mutation in exon } 9 \text { leads to } \\
\text { a C-G transversion, and } \\
\text { loss of two final amino } \\
\text { acids. Leads to increased } \\
\text { receptor binding and } \\
\text { endocytosis [68]. }\end{array}$ & & $5-12 \%$ [63]. & $\begin{array}{l}\text { Decreased TG, increased } \\
\text { HDL, reduced risk of CAD } \\
\text { and T2D [69]. Clinically } \\
\text { underrepresented in } \\
\text { patients with } \\
\text { diagnosed AD. }\end{array}$ \\
\hline
\end{tabular}

The HindIII (rs320) variant is located in intron 8, and removes the HindIII restriction enzyme recognition site (Table 1) [70]. The presence of the HindIII variant has been shown to impair transcription factor binding, leading to decreased LPL expression in vitro [71]. Specifically, the HindIII site is a putative TATA box, and subunits of TFIID and TATA-binding protein (TBP) have a reduced affinity for the variant sequence [71]. Moreover, HindIII (+/+) individuals have an increased risk of stroke, coronary artery disease, elevated levels of plasma TG, and reduced HDL-C [72]. However, recent analysis has suggested that HindIII (+/-) carriers may be protected against ischemic stroke (IS) [73]. In an Italian population, HindIII (+/+), but not HindIII (+/-) was associated with an increased risk of AD [66]. In an Iranian cohort, the frequency of the HindIII $(+/+)$ genotype was significantly higher in patients with 
LOAD than controls [65]. Indeed, there was a 1.75-fold increase of LOAD in HindIII (+/+), which was more pronounced in males [65].

The PvuII (rs285) SNP is found in intron 6 of the LPL gene and is associated with increased TG, HDL-C, diabetes, and coronary artery disease incidence and severity (Table 1) [67,74]. Screening of a large eastern Canadian cohort of autopsy-confirmed control and AD brains demonstrated a significant association between PvuII and sporadic AD [67]. Importantly, PvuII was associated with reduced cortical cholesterol concentrations, increased neurofibrillary tangles (NFTs), and increased senile plaques [67]. In addition, there was an interaction between senile plaque formation and the APOE4 allele in the fusiform gyrus [67]. While the effect of an intrinsic variation on protein function is unlikely, the fact that the PvuII restriction site is a non-coding cis-regulatory element is likely of functional significance. However, in silico analysis of PvuII suggest that this variant does not affect the splicing pattern of the LPL hnRNA, or hnRNA structure or stability [58].

Variant Ser447Ter (rs328), also known as S447X, occurs in exon 9 of the LPL gene and leads to a C-G transversion and a truncated version of the LPL protein that lacks the two final amino acids (Table 1). It has been suggested that the truncation of these amino acids in the C-terminal leads to exposure of amino acids 401-413, which represent putative lipoprotein receptor binding sites, and represent a mechanism of action of increased lipoprotein uptake and reduced CAD risk in individuals carrying this variant [68]. Unlike the mutations already discussed in this review, the S447X variant is associated with reduced TG, and reduced risk of developing CAD and T2D; indicative of a gain-of-function mutation $[75,76]$. However, the mechanism underlying this increased function is not fully understood. On one hand, in vitro studies using COS-1 cells to express the S447X variant have shown increased hydrolytic activity compared to WT (185\%) when ${ }^{3} \mathrm{H}$ triolein was used as a substrate [77]. In contrast, in vitro studies have also demonstrated no differences in the hydrolytic activity of LPL harboring the S447X variant (LPL ${ }^{\text {S447X }}$ ), or any greater susceptibility to ANGPTL4 mediated inhibition [68]. However, LPL ${ }^{S 447 X}$ is associated with increased LPL-mediated uptake of fluorescently labeled lipoprotein particles, suggesting that the truncation exposes residues involved in receptor binding and endocytosis [68]. In addition, these studies have reported both an increase in LPL mass (131\%) [78], and an increase in protein translation, due to reduced translation inhibition associated with the S447X variant [79]. Therefore, an increased abundance of LPL in individuals carrying the S447X mutation may account for the clinical benefit of this variant. However, it is also likely that major differences in the methods used to measure LPL activity may account for discrepancies in the literature regarding the functional effects of the S447X variant.

Due to its therapeutic potential, the S447X variant has been successfully administered in mice, and was the first approved gene therapy in humans (alipogene tiparvovec/glybera) aimed at reducing TG and alleviating symptoms (i.e., recurrent pancreatitis) in patients with LPL-deficiency. However, this drug was later pulled from the market due to the high cost of manufacturing. Interestingly, the S447X mutation is one of the most common and is found in $5-12 \%$ of the general population, with variances depending on the ethnic group [63]. Although there have been reports of a lack of association between the S447X mutation and AD risk [80], additional studies, including two meta-analyses indicating that LPL S447X may be underrepresented in patients with AD and therefore is a protective factor of $\mathrm{AD}[8,81]$. Since the S447X is associated with increased lipoprotein uptake, it is, therefore, plausible to speculate that increased clearance of lipoproteins in the brain may contribute to the possible protection from AD. In addition, increased LPL ${ }^{\text {S477X }}$-mediated endocytosis of APOE4 containing astrocyte-derived HDL may be protective in aging and disease. However, since CAD and AD share many clinical characteristics [82], the contribution of the S447X mutation to reduced AD risk may also be a result of indirect effects on peripheral metabolism.

\section{Genetic Variants Regulating LPL Function and Processing and AD Risk}

Altered LPL-mediated lipid and lipoprotein processing in the CNS, and periphery may contribute to $\mathrm{AD}$ risk. Therefore, it is not surprising that genetic (and epigenetic) variants of the proteins involved 
in LPL regulation and processing (discussed in detail above) are also associated with changes in $\mathrm{AD}$ risk.

The best-characterized genetic determinant of familial AD (FAD) and LOAD is the apolipoprotein E (ApoE) allele epsilon 4 (APOE4). It is thought that this variant plays several roles in the neuropathogenesis of $\mathrm{AD}$, including alterations in microglial lipid and lipoprotein metabolism and microglial function leading to reduced clearance of $A \beta$ [83]. The role of APOE4 in the pathobiology of AD has been extensively reviewed elsewhere [84]. However, although an interaction between APOE4 and the potential inhibition by APOE-containing lipoproteins on LPL-mediated lipoprotein metabolism in the brain is plausible, this has not yet been directly studied.

There are only a few reports of genetic variants in the ApoC family and AD risk. The Taq1 "F allele" of the ApoC-II gene is positively associated with Alzheimer's dementia [85]. Further analysis has revealed that the ApoC-II F allele is positively associated with late-onset AD (LOAD), but not early-onset FAD [86]. In addition, an interaction between ApoC-II and APOE in late-onset FAD has been described [87]. Since ApoC-II is a known LPL activator, the association between a dysfunctional ApoC-II variant and AD suggests reduced LPL-mediated lipid processing; however, this remains to be studied. Consistent with this hypothesis, it has been noted that the rare ApoC-III "G allele" variant may offer some protection against the development of sporadic AD (SAD) in a Chinese population [88].

Several recent studies have highlighted a role for SORL1 in the development of both late-onset and early-onset AD [89,90]. Specifically, SORL1 expression is reduced in SAD [91]. Since SORL1 is involved in neuronal endosomal trafficking, it is thought that functional variants in SORL1 lead to defects in A $\beta$ and APP processing [92,93]. Moreover, loss of function mutations are thought to cause LOAD [94]. Since SORL1 is also associated with LPL trafficking and secretion, it would be of interest to determine whether there was a synergistic interaction between these two proteins regarding AD risk. However, SORL1 is involved in the intracellular trafficking of many factors, including enzymes, growth factors, and signaling receptors, and is not specific to LPL. Therefore, LPL-specific interactions may be challenging to discriminate [95].

\section{LPL Variants and Other CNS Disorders}

LPL polymorphisms have also been implicated in other CNS disorders such as vascular dementia and ischemic stroke (IS) [58,73]. While the mechanisms may be distinct from the development of $\mathrm{AD}$, evaluating the role of gain, and loss-of-function mutations may shed light on the etiology of the disease and the function of LPL in the CNS. For example, recent studies suggest that individuals with the HindIII(+/+) and PvuIII mutations, which are thought to be detrimental to LPL function, may be protected against IS [65,73]. In contrast, the "gain-of-function" Ser447Ter polymorphism is not associated with a reduced risk of IS, suggesting that LPL-mediated lipoprotein uptake may exacerbate stroke risk [65]. However, inconsistent observations have been reported [72], prompting the need for further study.

LPL-dependent regulation of lipid and lipoprotein metabolism in the brain may influence neuronal function and metabolism, astrocyte metabolism, microglial lipid metabolism, phagocytosis, and immunomodulation (gliosis). Therefore, altered expression, processing or function of LPL has the potential to underlie the pathogenesis of many CNS disorders such as AD, MS, Parkinson's disease, and beyond. While associations with LPL polymorphisms and AD have been reported, there have been no reports (at the time of publication of this manuscript) that link LPL mutations with any other neurodegenerative disease. However, since altered abundance of LPL has been repeatedly implicated in $\mathrm{AD}$ and demyelinating disorders, metabolic diseases, and aging, it is likely that further study may reveal additional associations with functional LPL mutations.

\section{Conclusions}

In summary, there have been a number of reports linking LPL polymorphisms to increased (loss of function mutations [N291S]) or reduced (increased LPL function [S447X]) AD risk. While the 
mechanism of action is still under investigation, these findings suggest that functional LPL is protective against the development of AD. Recent insights into the structure and function of LPL suggest that the S447X variant offers protection via increased lipoprotein uptake. Moreover, loss of function mutations in ApoC-II, which activates LPL is associated with increased AD risk. In contrast, mutations in ApoC-III, which inhibits LPL activity, is protective, further supporting the notion of a protective role for functional LPL in AD pathogenesis. Further basic studies are needed to address functional differences and to empirically determine the role of LPL in AD neuropathogenesis.

Author Contributions: K.D.B., M.T., P.R. and R.H.E. wrote the paper. All authors have read and agreed to the published version of the manuscript.

Funding: This research was funded by the NIH, with grants awarded to K.D.B. (5KL2TR002534-02, 10/10/2018) and K.D.B and R.H.E (R21AG061549-01, 12/1/2018).

Conflicts of Interest: The authors declare no conflict of interest.

\section{Abbreviations}

LPL

$\mathrm{A} \beta$

$\mathrm{AD}$

ApoC-II

ApoC-III

ChEIs

DMTs

TG

VLDL

CVD

CNS

OPCs

GPIHBP

TRL

LMF1

FFAs

LRP

RAP

HSPGs

ANGPTL $(3,4,8)$

HDL

DOCK

APOE

CLU

ApoJ

TREM2

PUFAs

SORLA

MS

DAMS

PAMS

FCS

LOAD

CAD

SAD
Lipoprotein Lipase

Amyloid-Beta

Alzheimer's Disease

ApoproteinC-II

ApoproteinC-III

Cholinesterase inhibitors

Disease-modifying therapeutics

Triglycerides

Very-low-density lipoprotein

Cardiovascular Disease

Central Nervous system

Oligodendrocytes

Glycosylphosphatidylinositol-anchored high-density lipoprotein binding protein 1

Triglyceride-rich lipoproteins

Lipoprotein Maturation factor 1

Free Fatty Acids

LDL receptor-related protein/ $\alpha 2$-macroglobulin receptor LRP2

Receptor associated protein

Heparan sulfate proteoglycans

Angiopoietin-like protein $(3,4,8)$

High-density lipoproteins

Dedicator of cytokinesis

Apoprotein E

Clusterin

Apoprotein J

Triggering receptor expressed on myeloid cells

Polyunsaturated fatty acids

Sortilin

Multiple Sclerosis

Disease Associated Microglia

Proliferative-region-associated-microglia

Familial chylomicronemia syndrome

Late onset AD

Coronary Artery Disease

Sporadic AD 


\section{References}

1. Hebert, L.E.; Weuve, J.; Scherr, P.A.; Evans, D.A. Alzheimer disease in the United States (2010-2050) estimated using the 2010 census. Neurology 2013, 80, 1778-1783. [CrossRef] [PubMed]

2. Holtzman, D.M.; Morris, J.C.; Goate, A.M. Alzheimer's Disease: The Challenge of the Second Century. Sci. Transl. Med. 2011, 3, 77sr1. [CrossRef] [PubMed]

3. Bessesen, D.H.; Richards, C.L.; Etienne, J.; Goers, J.W.; Eckel, R.H. Spinal cord of the rat contains more lipoprotein lipase than other brain regions. J. Lipid Res. 1993, 34, 229-238. [PubMed]

4. Eckel, R.H.; Robbins, R.J. Lipoprotein lipase is produced, regulated, and functional in rat brain. Proc. Natl. Acad. Sci. USA 1984, 81, 7604-7607. [CrossRef] [PubMed]

5. Goldberg, I.J.; Soprano, D.R.; Wyatt, M.L.; Vanni, T.M.; Kirchgessner, T.G.; Schotz, M.C. Localization of lipoprotein lipase mRNA in selected rat tissues. J. Lipid Res. 1989, 30, 1569-1577.

6. Zhang, Y.; Chen, K.; Sloan, S.A.; Bennett, M.L.; Scholze, A.R.; O’Keeffe, S.; Phatnani, H.P.; Guarnieri, P.; Caneda, C.; Ruderisch, N.; et al. An RNA-Sequencing Transcriptome and Splicing Database of Glia, Neurons, and Vascular Cells of the Cerebral Cortex. J. Neurosci. 2014, 34, 11929-11947. [CrossRef] [PubMed]

7. Zhang, Y.; Sloan, S.A.; Clarke, L.E.; Caneda, C.; Plaza, C.A.; Blumenthal, P.D.; Vogel, H.; Steinberg, G.K.; Edwards, M.S.B.; Li, G.; et al. Purification and Characterization of Progenitor and Mature Human Astrocytes Reveals Transcriptional and Functional Differences with Mouse. Neuron 2016, 89, 37-53. [CrossRef]

8. Ren, L.; Ren, X. Meta-analyses of four polymorphisms of lipoprotein lipase associated with the risk of Alzheimer's disease. Neurosci. Lett. 2016, 619, 73-78. [CrossRef]

9. Baum, L.; Wiebusch, H.; Pang, C.P. Roles for lipoprotein lipase in Alzheimer's disease: An association study. Microsc. Res. Tech. 2000, 50, 291-296. [CrossRef]

10. Gao, Y.; Vidal-Itriago, A.; Kalsbeek, M.J.; Layritz, C.; Garcia-Caceres, C.; Tom, R.Z.; Eichmann, T.O.; Vaz, F.M.; Houtkooper, R.H.; Van Der Wel, N.; et al. Lipoprotein Lipase Maintains Microglial Innate Immunity in Obesity. Cell Rep. 2017, 20, 3034-3042. [CrossRef]

11. Keren-Shaul, H.; Spinrad, A.; Weiner, A.; Matcovitch-Natan, O.; Dvir-Szternfeld, R.; Ulland, T.K.; David, E.; Baruch, K.; Lara-Astaiso, D.; Toth, B.; et al. A Unique Microglia Type Associated with Restricting Development of Alzheimer's Disease. Cell 2017, 169, 1276-1290.e17. [CrossRef] [PubMed]

12. Bruce, K.D.; Gorkhali, S.; Given, K.; Coates, A.M.; Boyle, K.E.; Macklin, W.B.; Eckel, R.H. Lipoprotein Lipase Is a Feature of Alternatively-Activated Microglia and May Facilitate Lipid Uptake in the CNS During Demyelination. Front. Mol. Neurosci. 2018, 11, 57. [CrossRef] [PubMed]

13. Ma, Y.; Bao, J.; Zhao, X.; Shen, H.; Lv, J.; Ma, S.; Zhang, X.; Li, Z.; Wang, S.; Wang, Q.; et al. Activated Cyclin-Dependent Kinase 5 Promotes Microglial Phagocytosis of Fibrillar $\beta$-Amyloid by Up-regulating Lipoprotein Lipase Expression. Mol. Cell. Proteom. 2013, 12, 2833-2844. [CrossRef]

14. Arora, R.; Nimonkar, A.V.; Baird, D.; Wang, C.; Chiu, C.-H.; Horton, P.A.; Hanrahan, S.; Cubbon, R.; Weldon, S.; Tschantz, W.R.; et al. Structure of lipoprotein lipase in complex with GPIHBP1. Proc. Natl. Acad. Sci. USA 2019, 116, 10360-10365. [CrossRef] [PubMed]

15. Chen, T.-Z.; Xie, S.-L.; Jin, R.; Huang, Z.-M. A novel lipoprotein lipase gene missense mutation in Chinese patients with severe hypertriglyceridemia and pancreatitis. Lipids Health Dis. 2014, 13, 52. [CrossRef]

16. Kobayashi, Y.; Nakajima, T.; Inoue, I. Molecular modeling of the dimeric structure of human lipoprotein lipase and functional studies of the carboxyl-terminal domain. JBIC J. Biol. Inorg. Chem. 2002, 269, 4701-4710. [CrossRef]

17. Iverius, P.H.; Ostlund-Lindqvist, A.M. Lipoprotein lipase from bovine milk. Isolation procedure, chemical characterization, and molecular weight analysis. J. Biol. Chem. 1976, 251, 7791-7795.

18. Van Tilbeurgh, H.; Roussel, A.; Lalouel, J.M.; Cambillau, C. Lipoprotein lipase. Molecular model based on the pancreatic lipase $\mathrm{x}$-ray structure: Consequences for heparin binding and catalysis. J. Biol. Chem. 1994, 269, 4626-4633.

19. Birrane, G.; Beigneux, A.P.; Dwyer, B.; Strack-Logue, B.; Kristensen, K.K.; Francone, O.L.; Fong, L.G.; Mertens, H.D.T.; Pan, C.Q.; Ploug, M.; et al. Structure of the lipoprotein lipase-GPIHBP1 complex that mediates plasma triglyceride hydrolysis. Proc. Natl. Acad. Sci. USA 2019, 116, 1723-1732. [CrossRef]

20. Doolittle, M.H.; Ehrhardt, N.; Péterfy, M. Lipase maturation factor 1: Structure and role in lipase folding and assembly. Curr. Opin. Lipidol. 2010, 21, 198-203. [CrossRef] 
21. Roberts, B.S.; Babilonia-Rosa, M.A.; Broadwell, L.J.; Wu, M.J.; Neher, S.B. Lipase maturation factor 1 affects redox homeostasis in the endoplasmic reticulum. EMBO J. 2018, 37, e97379. [CrossRef]

22. Ishibashi, S.; Yamada, N.; Shimano, H.; Mori, N.; Mokuno, H.; Gotohda, T.; Kawakami, M.; Murase, T.; Takaku, F. Apolipoprotein E and lipoprotein lipase secreted from human monocyte-derived macrophages modulate very low density lipoprotein uptake. J. Biol. Chem. 1990, 265, 3040-3047. [PubMed]

23. Medh, J.D.; Bowen, S.L.; Fry, G.L.; Ruben, S.; Andracki, M.; Inoue, I.; Lalouel, J.-M.; Strickland, D.K.; Chappell, D.A. Lipoprotein Lipase Binds to Low Density Lipoprotein Receptors and Induces Receptor-mediated Catabolism of Very Low Density Lipoproteinsin Vitro. J. Biol. Chem. 1996, 271, 17073-17080. [CrossRef]

24. Nielsen, M.S.; Jacobsen, C.; Olivecrona, G.; Gliemann, J.; Petersen, C.M. Sortilin/Neurotensin Receptor-3 Binds and Mediates Degradation of Lipoprotein Lipase. J. Biol. Chem. 1999, 274, 8832-8836. [CrossRef]

25. Page, S.T.; Judson, A.; Melford, K.; Bensadoun, A. Interaction of Lipoprotein Lipase and Receptor-associated Protein. J. Biol. Chem. 2006, 281, 13931-13938. [CrossRef]

26. Mysling, S.; Kristensen, K.K.; Larsson, M.; Kovrov, O.; Bensadouen, A.; Jorgensen, T.J.D.; Olivecrona, G.; Young, S.G.; Ploug, M. The angiopoietin-like protein ANGPTL4 catalyzes unfolding of the hydrolase domain in lipoprotein lipase and the endothelial membrane protein GPIHBP1 counteracts this unfolding. eLife 2016, 5, e20958. [CrossRef]

27. Mysling, S.; Kristensen, K.K.; Larsson, M.; Beigneux, A.P.; Gårdsvoll, H.; Fong, L.G.; Bensadouen, A.; Jørgensen, T.J.D.; Young, S.G.; Ploug, M. The acidic domain of the endothelial membrane protein GPIHBP1 stabilizes lipoprotein lipase activity by preventing unfolding of its catalytic domain. eLife 2016, 5, e12095. [CrossRef] [PubMed]

28. Kristensen, K.K.; Leth-Espensen, K.Z.; Young, S.G.; Ploug, M. ANGPTL4 inactivates lipoprotein lipase by catalyzing the irreversible unfolding of LPL's hydrolase domain. J. Lipid Res. 2020, 61, 1253. [CrossRef] [PubMed]

29. Shimamura, M.; Matsuda, M.; Yasumo, H.; Okazaki, M.; Fujimoto, K.; Kono, K.; Shimizugawa, T.; Ando, Y.; Koishi, R.; Kohama, T.; et al. Angiopoietin-Like Protein3 Regulates Plasma HDL Cholesterol Through Suppression of Endothelial Lipase. Arter. Thromb. Vasc. Biol. 2007, 27, 366-372. [CrossRef]

30. Shimizugawa, T.; Ono, M.; Shimamura, M.; Yoshida, K.; Ando, Y.; Koishi, R.; Ueda, K.; Inaba, T.; Minekura, H.; Kohama, T.; et al. ANGPTL3 Decreases Very Low Density Lipoprotein Triglyceride Clearance by Inhibition of Lipoprotein Lipase. J. Biol. Chem. 2002, 277, 33742-33748. [CrossRef] [PubMed]

31. Quagliarini, F.; Wang, Y.; Kozlitina, J.; Grishin, N.V.; Hyde, R.; Boerwinkle, E.; Valenzuela, D.M.; Murphy, A.J.; Cohen, J.C.; Hobbs, H.H. Atypical angiopoietin-like protein that regulates ANGPTL3. Proc. Natl. Acad. Sci. USA 2012, 109, 19751-19756. [CrossRef]

32. Larsson, M.; Vorrsjö, E.; Talmud, P.J.; Lookene, A.; Olivecrona, G. Apolipoproteins C-I and C-III Inhibit Lipoprotein Lipase Activity by Displacement of the Enzyme from Lipid Droplets*. J. Biol. Chem. 2013, 288, 33997-34008. [CrossRef]

33. Rensen, P.C.; Van Berkel, T.J.C. Apolipoprotein E Effectively Inhibits Lipoprotein Lipase-mediated Lipolysis of Chylomicron-like Triglyceride-rich Lipid Emulsionsin Vitroandin Vivo. J. Biol. Chem. 1996, 271, 14791-14799. [CrossRef]

34. Merkel, M.; Loeffler, B.; Kluger, M.; Fabig, N.; Geppert, G.; Pennacchio, L.A.; Laatsch, A.; Heeren, J. Apolipoprotein AV Accelerates Plasma Hydrolysis of Triglyceriderich Lipoproteins by Interaction with Proteoglycan-bound Lipoprotein Lipase. J. Biol. Chem. 2005, 280, 21553-21560. [CrossRef]

35. Goldberg, I.J.; Scheraldi, C.A.; Yacoub, L.K.; Saxena, U.; Bisgaier, C.L. Lipoprotein ApoC-II activation of lipoprotein lipase. Modulation by apolipoprotein A-IV. J. Biol. Chem. 1990, 265, 4266-4272.

36. Kinnunen, P.K.; Jackson, R.L.; Smith, L.C.; Gotto, A.M.; Sparrow, J.T. Activation of lipoprotein lipase by native and synthetic fragments of human plasma apolipoprotein C-II. Proc. Natl. Acad. Sci. USA 1977, 74, 4848-4851. [CrossRef]

37. Lambert, J.-C.; The European Alzheimer's Disease Initiative Investigators; Heath, S.; Even, G.; Campion, D.; Sleegers, K.; Hiltunen, M.O.; Combarros, O.; Zelenika, D.; Bullido, M.J.; et al. Genome-wide association study identifies variants at CLU and CR1 associated with Alzheimer's disease. Nat. Genet. 2009, 41, 1094-1099. [CrossRef]

38. Harold, D.; Abraham, R.; Hollingworth, P.; Sims, R.; Gerrish, A.; Hamshere, M.L.; Pahwa, J.S.; Moskvina, V.; Dowzell, K.; Williams, A.; et al. Genome-wide association study identifies variants at CLU and PICALM associated with Alzheimer's disease. Nat. Genet. 2009, 41, 1088-1093. [CrossRef] 
39. Zandl-Lang, M.; Fanaee-Danesh, E.; Sun, Y.; Albrecher, N.M.; Gali, C.C.; Čančar, I.; Kober, A.; Tam-Amersdorfer, C.; Stracke, A.; Storck, S.M.; et al. Regulatory effects of simvastatin and apoJ on APP processing and amyloid- $\beta$ clearance in blood-brain barrier endothelial cells. Biochim. Biophys. Acta (BBA)-Mol. Cell Biol. Lipids 2018, 1863, 40-60. [CrossRef]

40. Mulder, S.D.; Nielsen, H.M.; Blankenstein, M.; Eikelenboom, P.; Veerhuis, R. Apolipoproteins E and J interfere with amyloid-beta uptake by primary human astrocytes and microgliain vitro. Glia 2014, 62, 493-503. [CrossRef]

41. Foster, E.M.; Dangla-Valls, A.; Lovestone, S.; Ribe, E.M.; Buckley, N.J. Clusterin in Alzheimer's Disease: Mechanisms, Genetics, and Lessons from Other Pathologies. Front. Neurosci. 2019, 13, 164. [CrossRef]

42. Yerbury, J.J.; Wilson, M.R. Extracellular chaperones modulate the effects of Alzheimer's patient cerebrospinal fluid on A $\beta 1-42$ toxicity and uptake. Cell Stress Chaperones 2009, 15, 115-121. [CrossRef]

43. Yeh, F.L.; Wang, Y.; Tom, I.; Gonzalez, L.C.; Sheng, M. TREM2 Binds to Apolipoproteins, Including APOE and CLU/APOJ, and Thereby Facilitates Uptake of Amyloid-Beta by Microglia. Neuron 2016, 91, 328-340. [CrossRef]

44. Laperrousaz, E.; Moullé, V.S.; Denis, R.G.P.; Kassis, N.; Berland, C.; Colsch, B.; Fioramonti, X.; Philippe, E.; Lacombe, A.; Vanacker, C.; et al. Lipoprotein lipase in hypothalamus is a key regulator of body weight gain and glucose homeostasis in mice. Diabetology 2017, 60, 1314-1324. [CrossRef]

45. Wang, H.; Astarita, G.; Taussig, M.D.; Bharadwaj, K.G.; DiPatrizio, N.V.; Nave, K.-A.; Piomelli, D.; Goldberg, I.J.; Eckel, R.H. Deficiency of Lipoprotein Lipase in Neurons Modifies the Regulation of Energy Balance and Leads to Obesity. Cell Metab. 2011, 13, 105-113. [CrossRef]

46. Yu, T.; Taussig, M.D.; DiPatrizio, N.V.; Astarita, G.; Piomelli, D.; Bergman, B.C.; Dell'Acqua, M.L.; Eckel, R.H.; Wang, H. Deficiency of Lipoprotein Lipase in Neurons Decreases AMPA Receptor Phosphorylation and Leads to Neurobehavioral Abnormalities in Mice. PLoS ONE 2015, 10, e0135113. [CrossRef]

47. Bruce, K.D.; Dobrinskikh, E.; Wang, H.; Rudenko, I.; Gao, H.; Libby, A.E.; Gorkhali, S.; Yu, T.; Zsombok, A.; Eckel, R.H. Neuronal Lipoprotein Lipase Deficiency Alters Neuronal Function and Hepatic Metabolism. Metabolites 2020, 10, 385. [CrossRef]

48. Klinger, S.C.; Glerup, S.; Raarup, M.K.; Mari, M.C.; Nyegaard, M.; Koster, G.; Prabakaran, T.; Nilsson, S.K.; Kjaergaard, M.M.; Bakke, O.; et al. SorLA regulates the activity of lipoprotein lipase by intracellular trafficking. J. Cell Sci. 2011, 124, 1095-1105. [CrossRef]

49. Gao, Y.; Layritz, C.; Legutko, B.; Eichmann, T.O.; Laperrousaz, E.; Moullé, V.S.; Cruciani-Guglielmacci, C.; Magnan, C.; Luquet, S.; Woods, S.C.; et al. Disruption of Lipid Uptake in Astroglia Exacerbates Diet-Induced Obesity. Diabetes 2017, 66, 2555-2563. [CrossRef]

50. Nishitsuji, K.; Hosono, T.; Uchimura, K.; Michikawa, M. Lipoprotein Lipase Is a Novel Amyloid $\beta$ (A $\beta$ )-binding Protein That Promotes Glycosaminoglycan-dependent Cellular Uptake of A $\beta$ in Astrocytes. J. Biol. Chem. 2010, 286, 6393-6401. [CrossRef]

51. Kamermans, A.; Rijnsburger, M.; Chakraborty, A.; Van Der Pol, S.; De Vries, H.E.; Van Horssen, J. Reduced Angiopoietin-Like 4 Expression in Multiple Sclerosis Lesions Facilitates Lipid Uptake by Phagocytes via Modulation of Lipoprotein-Lipase Activity. Front. Immunol. 2019, 10. [CrossRef]

52. Grabert, K.; Michoel, T.; Karavolos, M.H.; Clohisey, S.; Baillie, J.K.; Stevens, M.P.; Freeman, T.; Summers, K.M.; McColl, B.W. Microglial brain region-dependent diversity and selective regional sensitivities to aging. Nat. Neurosci. 2016, 19, 504-516. [CrossRef]

53. Hammond, T.R.; Dufort, C.; Dissing-Olesen, L.; Giera, S.; Young, A.; Wysoker, A.; Walker, A.J.; Gergits, F.; Segel, M.; Nemesh, J.; et al. Single-Cell RNA Sequencing of Microglia throughout the Mouse Lifespan and in the Injured Brain Reveals Complex Cell-State Changes. Immunity 2019, 50, 253-271.e6. [CrossRef]

54. Li, Q.; Cheng, Z.; Zhou, L.; Darmanis, S.; Neff, N.F.; Okamoto, J.; Gulati, G.; Bennett, M.L.; Sun, L.O.; Clarke, L.; et al. Developmental Heterogeneity of Microglia and Brain Myeloid Cells Revealed by Deep Single-Cell RNA Sequencing. Neuron 2019, 101, 207-223.e10. [CrossRef]

55. Mathys, H.; Adaikkan, C.; Gao, F.; Young, J.Z.-N.; Manet, E.; Hemberg, M.; De Jager, P.L.; Ransohoff, R.M.; Regev, A.; Tsai, L.-H. Temporal Tracking of Microglia Activation in Neurodegeneration at Single-Cell Resolution. Cell Rep. 2017, 21, 366-380. [CrossRef]

56. Chait, A.; Eckel, R.H. The Chylomicronemia Syndrome Is Most Often Multifactorial. Ann. Intern. Med. 2019, 170, 626-634. [CrossRef] 
57. Xie, C.; Wang, Z.C.; Liu, X.F.; Wang, L.; Yang, M.S. Association between schizophrenia and single nucleotide polymorphisms in lipoprotein lipase gene in a Han Chinese population. Psychiatr. Genet. 2011, 21, 307-314. [CrossRef]

58. Nejati, M.; Atlasi, M.A.; Karimian, M.; Nikzad, H.; Tameh, A.A. Lipoprotein lipase gene polymorphisms as risk factors for stroke: A computational and meta-analysis. Iran J. Basic Med. Sci. 2018, 21, 701-708.

59. Van Bockxmeer, F. Lipoprotein lipase D9N, N291S and S447X polymorphisms: Their influence on premature coronary heart disease and plasma lipids. Atherosclerosis 2001, 157, 123-129. [CrossRef]

60. Hoffer, M.J.; Bredie, S.J.; Boomsma, D.I.; Reymer, P.W.; Kastelein, J.J.; De Knijff, P.; Demacker, P.N.; Stalenhoef, A.F.; Havekes, L.M.; Frants, R.R. The lipoprotein lipase (Asn291 $\rightarrow$ Ser) mutation is associated with elevated lipid levels in families with familial combined hyperlipidaemia. Atherosclerosis 1996, 119, 159-167. [CrossRef]

61. Fisher, R.M.; Mailly, F.; Peacock, R.E.; Hamsten, A.; Seed, M.; Yudkin, J.S.; Beisiegel, U.; Feussner, G.; Miller, G.; Humphries, S.E. Interaction of the lipoprotein lipase asparagine 291->serine mutation with body mass index determines elevated plasma triacylglycerol concentrations: A study in hyperlipidemic subjects, myocardial infarction survivors, and healthy adults. J. Lipid Res. 1995, 36, 2104-2112.

62. Reymer, P.W.; Groenemeyer, B.E.; Gagné, E.; Miao, L.; Appelman, E.E.; Seidel, J.C.; Kromhout, D.; Bijvoet, S.M.; Van De Oever, K.; Bruin, T.; et al. A frequently occurring mutation in the lipoprotein lipase gene (Asn291Ser) contributes to the expression of familial combined hyperlipidemia. Hum. Mol. Genet. 1995, 4, 1543-1549. [CrossRef]

63. Baum, L.; Chen, L.; Masliah, E.; Chan, Y.S.; Ng, H.-K.; Pang, C.P. Lipoprotein lipase mutations and Alzheimer's disease. Am. J. Med Genet. 1999, 88, 136-139. [CrossRef]

64. Wittekoek, M.E.; Pimstone, S.N.; Reymer, P.W.A.; Feuth, L.; Botma, G.-J.; Defesche, J.C.; Prins, M.; Hayden, M.R.; Kastelein, J.J.P. A Common Mutation in the Lipoprotein Lipase Gene (N291S) Alters the Lipoprotein Phenotype and Risk for Cardiovascular Disease in Patients with Familial Hypercholesterolemia. Circulation 1998, 97, 729-735. [CrossRef] [PubMed]

65. Sayad, A.; Noruzinia, M.; Zamani, M.; Harirchian, M.H.; Kazemnejad, A. Lipoprotein Lipase HindIII Intronic Polymorphism in a Subset of Iranian Patients with Late-Onset Alzheimer's Disease. Cell J. 2012, 14, 67-72.

66. Scacchi, R.; Gambina, G.; Broggio, E.; Moretto, G.; Ruggeri, M.; Corbo, R.M. The H+ allele of the lipoprotein lipase (LPL) HindIII intronic polymorphism and the risk for sporadic late-onset Alzheimer's disease. Neurosci. Lett. 2004, 367, 177-180. [CrossRef]

67. Blain, J.-F.; Aumont, N.; Théroux, L.; Dea, D.; Poirier, J. A polymorphism in lipoprotein lipase affects the severity of Alzheimer's disease pathophysiology. Eur. J. Neurosci. 2006, 24, 1245-1251. [CrossRef]

68. Hayne, C.K.; Lafferty, M.J.; Eglinger, B.J.; Kane, J.P.; Neher, S.B. Biochemical Analysis of the Lipoprotein Lipase Truncation Variant, LPLS447X, Reveals Increased Lipoprotein Uptake. Biochemistry 2017, 56, 525-533. [CrossRef]

69. Sawano, M.; Watanabe, Y.; Ohmura, H.; Shimada, K.; Daida, H.; Mokuno, H.; Yamaguchi, H. Potentially protective effects of the Ser447-Ter mutation of the lipoprotein lipase gene against the development of coronary artery disease in Japanese subjects via a beneficial lipid profile. Jpn. Circ. J. 2001, 65, 310-314. [CrossRef]

70. Gotoda, T.; Yamada, N.; Murase, T.; Shimano, H.; Shimada, M.; Harada, K.; Kawamura, M.; Kozaki, K.; Yazaki, Y. Detection of three separate DNA polymorphisms in the human lipoprotein lipase gene by gene amplification and restriction endonuclease digestion. J. Lipid Res. 1992, 33, 1067-1072.

71. Chen, Q.; Razzaghi, H.; Demirci, F.Y.; Kamboh, M.I. Functional significance of lipoprotein lipase HindIII polymorphism associated with the risk of coronary artery disease. Atherosclerosis 2008, 200, 102-108. [CrossRef]

72. Munshi, A.; Babu, M.S.; Kaul, S.; Rajeshwar, K.; Balakrishna, N.; Jyothy, A. Association of LPL gene variant and LDL, HDL, VLDL cholesterol and triglyceride levels with ischemic stroke and its subtypes. J. Neurol. Sci. 2012, 318, 51-54. [CrossRef]

73. Cao, L.; Li, Q.; Chen, X. The HindIII and PvuII polymorphisms of lipoprotein lipase (LPL) gene reduce the risk of ischemic stroke (IS). Medicine 2018, 97, e0483. [CrossRef] [PubMed]

74. Chamberlain, J.; Thorn, J.A.; Oka, K.; Galton, D.; Stocks, J. DNA polymorphisms at the lipoprotein lipase gene: Associations in normal and hypertriglyceridaemic subjects. Atherosclerosis 1989, 79, 85-91. [CrossRef] 
75. Liu, N.; Sang, Y.; Chen, S.; Liu, X. Associations of the LPL S447X and Hind III Polymorphism with Type 2 Diabetes Mellitus Risk: A Meta-Analysis. Horm. Metab. Res. 2020, 10, 1055. [CrossRef] [PubMed]

76. Ma, W.-Q.; Wang, Y.; Han, X.-Q.; Zhu, Y.; Liu, N.-F. Associations between LPL gene polymorphisms and coronary artery disease: Evidence based on an updated and cumulative meta-analysis. Biosci. Rep. 2018, 38. [CrossRef] [PubMed]

77. Kozaki, K.; Gotoda, T.; Kawamura, M.; Shimano, H.; Yazaki, Y.; Ouchi, Y.; Orimo, H.; Yamada, N. Mutational analysis of human lipoprotein lipase by carboxy-terminal truncation. J. Lipid Res. 1993, 34, 1765-1772.

78. Zhang, H.; Henderson, H.; Gagne, S.; Clee, S.M.; Miao, L.; Liu, G.; Hayden, M.R. Common sequence variants of lipoprotein lipase: Standardized studies of in vitro expression and catalytic function. Biochim. Biophys. Acta (BBA)-Lipids Lipid Metab. 1996, 1302, 159-166. [CrossRef]

79. Ranganathan, G.; Unal, R.; Pokrovskaya, I.D.; Tripathi, P.; Rotter, J.I.; Goodarzi, M.O.; Kern, P.A. The lipoprotein lipase (LPL) S447X gain of function variant involves increased mRNA translation. Atherosclerosis 2012, 221, 143-147. [CrossRef]

80. Martin-Rehrmann, M.D.; Cho, H.S.; Rebeck, G.W. Lack of association of two lipoprotein lipase polymorphisms with Alzheimer's disease. Neurosci. Lett. 2002, 328, 109-112. [CrossRef]

81. Xu, X.; Wang, Y.; Wang, L.; Liao, Q.; Chang, L.; Xu, L.; Huang, Y.; Ye, H.; Xu, L.; Chen, C.; et al. Meta-Analyses of 8 Polymorphisms Associated with the Risk of the Alzheimer's Disease. PLoS ONE 2013, 8, e73129. [CrossRef]

82. Lamar, M.; Boots, E.A.; Arfanakis, K.; Barnes, L.L.; Schneider, J.A. Common Brain Structural Alterations Associated with Cardiovascular Disease Risk Factors and Alzheimer's Dementia: Future Directions and Implications. Neuropsychol. Rev. 2020, 1-12. [CrossRef]

83. Konttinen, H.; Cabral-Da-Silva, M.E.C.; Ohtonen, S.; Wojciechowski, S.; Shakirzyanova, A.; Caligola, S.; Giugno, R.; Ishchenko, Y.; Hernández, D.; Fazaludeen, M.F.; et al. PSEN1 $\triangle E 9$, APPswe, and APOE4 Confer Disparate Phenotypes in Human iPSC-Derived Microglia. Stem Cell Rep. 2019, 13, 669-683. [CrossRef]

84. Yamazaki, Y.; Zhao, N.; Caulfield, T.R.; Liu, C.-C.; Bu, G. Apolipoprotein E and Alzheimer disease: Pathobiology and targeting strategies. Nat. Rev. Neurol. 2019, 15, 501-518. [CrossRef]

85. Schellenberg, G.D.; Deeb, S.S.; Boehnke, M.; Bryant, E.M.; Martin, G.M.; Lampe, T.H.; Bird, T.D. Association of an apolipoprotein CII allele with familial dementia of the Alzheimer type. J. Neurogenet. 1987, 4, 97-108. [CrossRef]

86. Schellenberg, G.D.; Boehnke, M.; Wijsman, E.M.; Moore, D.K.; Martin, G.M.; Bird, T.D. Genetic association and linkage analysis of the apolipoprotein CII locus and familial Alzheimer's disease. Ann. Neurol. 1992, 31, 223-227. [CrossRef]

87. Yu, C.-E.; Payami, H.; Olson, J.M.; Boehnke, M.; Wijsman, E.M.; Orr, H.T.; Kukull, W.A.; Goddard, K.A.B.; Nemens, E.; White, J.A.; et al. The Apolipoprotein E/CI/CII Gene Cluster and Late-Onset Alzheimer Disease. Am. J. Hum. Genet. 1994, 54, 631-642.

88. Sun, Y.; Shi, J.; Zhang, S.; Tang, M.; Han, H.; Guo, Y.; Ma, C.; Liu, X.; Li, T. The APOC3 SstI polymorphism is weakly associated with sporadic Alzheimer's disease in a Chinese population. Neurosci. Lett. 2005, 380, 219-222. [CrossRef]

89. Bettens, K.; Brouwers, N.; Engelborghs, S.; De Deyn, P.P.; Van Broeckhoven, C.; Sleegers, K. SORL1 is genetically associated with increased risk for late-onset Alzheimer disease in the Belgian population. Hum. Mutat. 2008, 29, 769-770. [CrossRef]

90. Verheijen, J.; Bossche, T.V.D.; Van Der Zee, J.; Engelborghs, S.; Sanchez-Valle, R.; Lladó, A.; Graff, C.; Thonberg, H.; Pastor, P.; Ortega-Cubero, S.; et al. A comprehensive study of the genetic impact of rare variants in SORL1 in European early-onset Alzheimer's disease. Acta Neuropathol. 2016, 132, 213-224. [CrossRef]

91. Ba, K.L.S.; Wuu, J.; Leurgans, S.E.; Rees, H.D.; Gearing, M.; Mufson, E.J.; Levey, A.I.; Lah, J.J.; Sager, K.L.; Levey, A.I. Neuronal LR11/sorLA expression is reduced in mild cognitive impairment. Ann. Neurol. 2007, 62, 640-647. [CrossRef]

92. Knupp, A.; Mishra, S.; Martinez, R.; Braggin, J.E.; Szabo, M.; Kinoshita, C.; Hailey, D.W.; Small, S.A.; Jayadev, S.; Young, J.E. Depletion of the AD Risk Gene SORL1 Selectively Impairs Neuronal Endosomal Traffic Independent of Amyloidogenic APP Processing. Cell Rep. 2020, 31, 107719. [CrossRef] 
93. Caglayan, S.; Takagi-Niidome, S.; Liao, F.; Carlo, A.-S.; Schmidt, V.; Burgert, T.; Kitago, Y.; Füchtbauer, E.-M.; Füchtbauer, A.; Holtzman, D.M.; et al. Lysosomal Sorting of Amyloid- by the SORLA Receptor Is Impaired by a Familial Alzheimer's Disease Mutation. Sci. Transl. Med. 2014, 6, 223ra20. [CrossRef]

94. Raghavan, N.S.; Brickman, A.M.; Andrews, H.; Manly, J.J.; Schupf, N.; Lantigua, R.; Wolock, C.J.; Kamalakaran, S.; Petrovski, S.; Tosto, G.; et al. Whole-exome sequencing in 20,197 persons for rare variants in Alzheimer's disease. Ann. Clin. Transl. Neurol. 2018, 5, 832-842. [CrossRef] [PubMed]

95. Schmidt, V.; Subkhangulova, A.; Willnow, T.E. Sorting receptor SORLA: Cellular mechanisms and implications for disease. Cell. Mol. Life Sci. 2016, 74, 1475-1483. [CrossRef]

Publisher's Note: MDPI stays neutral with regard to jurisdictional claims in published maps and institutional affiliations.

(C) 2020 by the authors. Licensee MDPI, Basel, Switzerland. This article is an open access article distributed under the terms and conditions of the Creative Commons Attribution (CC BY) license (http://creativecommons.org/licenses/by/4.0/). 